\title{
Digital Technologies in Education and Their Influence on Modern Society
}

\author{
V.B. Dzobelova \\ North Ossetian State University \\ named after Kosta Levanovich Khetagurov \\ Vladikavkaz, Russia \\ dzobelova@mail.ru
}

\section{A.V. Olisaeva}

North Ossetian State University

named after Kosta Levanovich Khetagurov

Vladikavkaz, Russia

alisa.olisaeva@mail.ru

\author{
L.A. Aguzarova \\ North Ossetian State University \\ named after Kosta Levanovich Khetagurov \\ Vladikavkaz, Russia \\ aguzarova.larisa@yandex.ru
}

\section{E.E.Kornilova}

St. Petersburg state University of Economics

Saint-Petersburg, Russia

qqq50@mail.ru

\begin{abstract}
Nowadays much attention is paid to assessing the results of students` educational activities. International surveys compile the ranking and compare not only universities but also countries. Transparent results, social reports, the desire for improving the existing standards indicate the current trend towards improving the quality of education. To a great extent, the technology of online learning has become the reason for transparency and the desire for self-improvement. It is hard to imagine modern education without the use of digital technologies. These are presentations, video lectures, computer testing, electronic courses and many others. In the modern world, continuing education is growing more and more urgent.

The article emphasizes the importance of using modern digital technologies in the field of education, electronic multimedia textbooks and video lessons. The features of electronic multimedia textbooks at the stage of the development of modern digital technologies are high mobility and correspondence to the model and flexibility in learning. The article presents international and Russian experience in the transformation of education, primarily through digital products and solutions, information and communication technologies. The positive and negative aspects of the use of digital technologies in the educational process are determined.
\end{abstract}

Keywords: e-learning, digital technologies, pedagogics, continuing education, innovation

\section{INTRODUCTION}

The whole world is connected with the modern information system. Digital technologies have become the center of the Fourth Industrial Revolution [1].
Digitization is a global tendency, that all states are adhering to, with the purpose of developing a competitive economy and improving the population`s life quality [2]

Digitization has great potential, capable of completely changing the methodology and each stage in the learning process. Online courses, training and innovative teaching methods in the field of higher education are especially in demand.

In 2017, the digital economy program is being implemented in the Russian Federation. Its main purpose is the creation and development of the digital environment. Teachers (the "Staff and Education" area), who form models of digital competence and possess it themselves, are especially important among professionals. It is planned not only to carry out training and continuing professional development of teachers, taking into account the competencies that are a priority for the digital economy but also to deploy advanced research and development in the direction of digital technologies use, a digital educational environment to expand the possibilities of professional pedagogics. Digital educational environment (DEE) is an open set of information systems designed to provide various tasks of the educational process. It is increasingly enlarged with digital teaching aids (interactive whiteboards, digital cameras, microscopes, projectors, computers, laboratories, virtual and augmented reality and many others). The list of tools is constantly updated with more advanced and technological aids.

Digital literacy is a person's readiness and ability to a reliable, efficient, critical and safe use of digital technologies in all areas of life [3]. Digital literacy is the basis of security in the information society and the most important part of education in the 21 st century. The formation of digital literacy 
In the next twenty years, a new design model for the should be developed alongside reading, quantitative and scientific literacy.

Among the interesting digital innovations should be noted the rapid adaptation of online learning, which is expressed in the form of the development of mixed learning (blended learning) and the active development of online courses MOOC (Massive on-line open course). The dynamics of the development of online learning is demonstrated, in particular, by the growth of available online courses, the number of which has doubled annually in recent years. Now more than 4200 courses are offered from more than 500 universities.

The emergence of a growing online segment of educational services can completely change the landscape of this sphere: in addition to the annual doubling of the number of courses offered and the number of students, the projected consolidated revenue of the MOOC market will increase by more than five times by 2020 , according to some estimates.

Additional areas of application of digital technologies in education are the development of digital libraries and digital university campuses, which are already implemented by many universities in America, Europe, and Russia [4].

In 2013, the European Commission launched a new initiative called Opening up Education, aimed at developing innovation and accelerating the informatization of schools and universities. The EU's Opening up Education program is aimed at implementing the latest achievements in digital education in the life of a European higher education: massively accessible online courses (Massive Open Online Courses), educational portals (Open Education Resources), open standards, and also means of continuous exchange of experience between students, teachers, educational institutions and IT business [5]

Mankind does not penetrate the «magical» world of digitization every year, but every month, even week and day [6]. Digitization technologies are new tools of the wonderful world that have not been previously used by mankind. These technologies are currently being developed.

\section{Methodology}

The fundamental source of the active use of digital technologies in the education system is its digitization. It is caused by the invasion of digital technologies and telecommunication systems in the human life, which contribute not only to the recording, processing, transfer, but also the creation of knowledge, the formation of skills in the form of "artificial intelligence." The leader in the application of artificial intelligence systems is the United States, whose transaction volume exceeds 6.4 billion dollars [7].

As a result, a significant part of new solutions in the education system will be implemented through educational services based on E-learning technologies. Simultaneously with the traditional classroom education system, a new transnational educational market for E-learning is being developed. It can quickly replace many elements of traditional educational systems and introduce new standards. development of educational services can be successful only if a cloud of interacting composite educational solutions appears that will allow performing the functions of a hybrid educational system based on the integrated use of "live" and "artificial" intelligence in the field of knowledge.

The urgency and relevance of the formulated hybrid educational system based on its digitization are due to very rapid growth in demand for the development of digital technologies for obtaining global, relevant, high-quality and high-demand competencies in a particular area of a person's professional activity. Therefore, the synthesis of globalization and personalization of total and permanent education, the country's population, its interactivity and focus on obtaining specific leadership knowledge and skills for students are now the basis of the strategy for the prospective development of educational institutions.

A unique European initiative is the European Institute for Innovation and Technology (EIT). This is an independent body of the European Union, whose activities are aimed at improving the competitiveness of Europe by stimulating the development of innovation, entrepreneurial skills and the support of new ideas. The «Horizon 2020» and «Horizon Europe» programs fund the Institute's activities. Knowledge and Innovation Communities (KICs) have been established based on the Institute. The purpose of this community is to strengthen the interaction between business, universities and research centers. The work of communities takes place in Innovation centers (Innovation hubs). Such centres are distributed throughout the European Union in order to increase the impact of the activities of the European Institute of innovation and technology [8].

In the process of intensive development of science, many corporations require employees who are ready to work at all levels of production using new technologies, and the need for employees who do not have special skills is lagging. Of course, the solution to these problems needs the modernization of the educational process.

\section{ANALISYS}

Currently, much attention is paid to assessing the results of students` educational activities. International surveys compile the ranking and compare not only universities but also countries [9]. Transparent results, social reports, the desire for improving the existing standards indicate the current trend towards improving the quality of education. To a great extent, the technology of online learning has become the reason for transparency and the desire for self-improvement.

Schools and universities are places where students acquire knowledge and do research. One of the main duties of a teacher is to attract young people to getting knowledge and understanding achievements. Currently, the method of "how" students learn seems more important than the "what" they learn, just as the way of learning seems more important than its content. Teaching, which promotes only learning, as copying knowledge, without the active participation of students or not causing their curiosity, cannot lead to discoveries and research. Education using research and 
Mundus Program, Alfa, Edulink, Tempus and others [12]. In the framework of cooperation in the field of higher education in Erasmus +, the following main areas are highlighted:

Key Action 1: Learning Mobility of Individuals - New Mobility Opportunities for Students and Teachers

Key Action 2: Cooperation for innovation and good practice - cooperation for developing the potential of universities and sharing best practices

as well as Jean Monnet Activities - wide opportunities for the development of European research in the framework of the Jean Monnet subprogram.

Erasmus + covers the so-called "Program countries", which includes:

- member countries of the European Union

- Iceland, Liechtenstein, Norway, Former Yugoslav Republic of Macedonia, Turkey, Serbia

as well as "partner countries", divided into 13 geographical regions:

\section{Region 1: Western Balkans}

Region 2: Eastern Partnership countries

\section{Region 3: Southern Mediterranean Countries}

Region 4: Russian Federation (territory recognized by international law)

and others, including Central Asia, Latin America, Africa, Caribbean countries.

Recently, the international level of higher education has been strengthened through agreements between countries and universities, which are supported by tools and programs that have been implemented by global international organizations. Experience in this area is characterized by several aspects: wider offers of courses, increased presence of foreign students, innovations in educational methodologies, as well as in the management of processes and research. Joint university courses with the participation of various universities are an effective tool for internationalization, as they allow exchanging ideas and experience, facilitate the meeting of different people (students, teachers and researchers) from different cultures and traditions, and allow developing the experience in universities that have different missions, visions and profiles. This is a new and growing development that raises many questions for institutions as for openness, teaching methods and research.

\section{RESULTS}

Modern education is hard to imagine without the use of digital technology [13]. These are presentations, video lectures, computer testing, e-learning courses and many others. Not everything is clear in the transition to digital technology. Like any changes, it has both positive and negative aspects. For example, the use of digital technology for distant learning is a definite advantage. Now distant learning has ceased to be taken seriously both by students and

Program, The Young in Action program, The Erasmus 
teachers. A lot of people consider it as a formality, although diplomas of higher education of external students do not differ from diplomas of regular students. If we engage external students in e-learning courses during semesters, and not only during sessions twice a year, then their training could become more effective. In the future, correspondence learning is likely to turn into distance learning.

In the modern world, continuing education is becoming more and more urgent; when receiving a diploma of higher education there are no guarantees that your speciality will always be in demand. Over time, you will need either to increase the level of professionalism or change the profession. Adults do not have the opportunity to learn in a classroom. Elearning courses could be useful in this case too. For this purpose, a modern university graduate must be able to learn, analyze, comprehend new material, have developed critical thinking, i.e. be prepared for self-development. Accessibility of education should be taken into account. Now anyone can find and listen to video lectures on the basic disciplines on the Internet that is given in various parts of the world.

In today's society, web applications are used more and more commonly in the management of personal knowledge. Over the past few years, digital skill, in its various aspects, remains the center of growing attention. Various reports and messages published by international organizations emphasized the importance of this particular skill of lifelong learning and participation in the so-called "information society".

What does it mean to be an educated person in the $21 \mathrm{st}$ century? This issue goes beyond the training of young people for future work and challenges, but it applies to conscious citizens, regardless of whether he was born or became a digitally savvy person, who is completely autonomous in accessing and using the resources, relationships, tools and potential of the digital society. Within this framework, skills are essential for managing and enriching our knowledge using online resources. This set of skills, which is defined as management of personal knowledge, combined with individual knowledge and the concepts of a personal educational network, should help each person choose and evaluate independently sources of information, search for online data and be able to store, process and transfer such data.

However, the value of contact learning should not be underestimated. If the way students learn is appropriate, the same applies to what they learn. The technology is not autonomous; all these tools and methods of digital learning have been developed by professional educators and specialists. Therefore, these developers should know how to choose the basic elements of cultural heritage that have been accumulated over time and how to present them to students. This approach is also applicable to the study of the main issues that humanity faced in the past. Otherwise, the risk may lie in providing a kind of training that focuses only on what seems to be useful now, because it is necessary according to conditional economic or social requirements, forgetting what is necessary for a human as a whole.

Digitization is connected with educational aids of digital technology, open to universities and schools that were not directly unavailable. Training using electronic multimedia textbooks and video lessons has a special place among them.

A feature of electronic multimedia textbooks at the stage of development of modern information technologies is high mobility and correspondence to the model and flexibility in learning. Electronic multimedia textbooks are a necessary tool to complement educational and research materials, fully suitable for additional use. Electronic multimedia textbooks can be used for the following purposes: digital certificate, electronic report, and visual material, textbook.

Teachers and students can work independently using an electronic multimedia textbook designed to use the capabilities of information technologies. Especially the use of this electronic multimedia textbook helps to increase students' interest in lessons, individual learning of topics without a teacher's instruction and preliminary preparation for laboratory work. When using an electronic multimedia textbook, the user's interface in the form of graphic design and a dialogue box increases students' interest in using this book.

Currently, the electronic multimedia textbook is the first among all learning systems. This does not exclude traditional forms of learning but suggests the need to replenish new forms of learning using digital technologies.

Video lessons provide a visual representation of the didactic opportunities for conducting classes based on digital teaching technologies. At the same time, both tasks of educational and methodological support of educational programs and the advanced training of teachers are solved.

Video lessons take a special place both in the main educational process and in the advanced training courses. Students get the opportunity to control directly a specific scientific process, even if there is an Internet connection, which is an integral part of many video lessons.

\section{CONCLUSION}

In summary, any digital technology is considered on a philosophical basis. Therefore, first of all, it is necessary to regulate, systematize and sort innovation technologies that have entered the world of knowledge. The results obtained by applying new methods and techniques in the lesson are the following: students' interest in learning increases, business skills, mental activity, resourcefulness, self-confidence are formed, students learn to express their thoughts systematically and all these contribute to the increase of the innovative knowledge level.

Digital technologies in education are not limited only to the use of digital devices, they facilitate the interaction between teacher and student, teacher and student, lecturer and student, which increases the effectiveness, and hence the quality of the educational process, interaction and efficiency. Digital education creates new opportunities for personalized learning, new models of cooperation are emerging, and a wider range of innovative and attractive learning strategies for students is becoming.

In the learning process, a new opportunity appeared to create new approaches, methods, models of training and 
[3] J. Basl, "Penetration of Industry 4.0 Principles into ERP Vendors' Products and Services - A Central European Study", Proceedings of the International Conference on Research and Practical Issues of Enterprise Information Systems, 2017. DOI: http://dx.doi.org/10.1007/978-3-31994845-4_8.

[4] J. Basl and P. Doucek, "A Metamodel for Evaluating Enterprise Readiness in the Context of Industry 4.0. Information", 2019, 10(3). DOI: http://dx.doi.org/10.3390/info10030089.

[5] O. Ena and G. Abdrakhmanova, "ICT through the prism of critical technologies", Foresight, 2017, vol. 19, no. 2, pp. 121-138.

[6] P. Doucek and J. Hološka, "Digital economy and industry 4.0 IDIMT2019", Innovation and Transformation in a Digital World, 27th Interdisciplinary Information Management Talks (Sept. 4-6, 2019, Kutná Hora, Czech Republic, TRAUNER Druck GmbH and Co KG, Linz, 2019, pp. 33-39.

[7] L. Gerlitz, "Design management as a domain of smart and sustainable enterprise: business modelling forinnovation and smart growth in Industry 4.0", Entrepreneurship and Sustainability, 2016, issues 3 (3), pp. 244-268. DOI: https://doi.org/10.9770/jesi.2016.3.3(3)

[8] M. Ignatiev, E. Karlik, E. Iakovleva, and V. Platonov, "Linguocombinatorial model for diagnosing the state of human resources in the digital economy", In the book: Proceedings of 2018 17th Russian Scientific and Practical Conference on Planning and Teaching Engineering Staff for the Industrial and Economic Complex of the Region, PTES 2018, 17, pp. 201-204.

[9] A. Issa, B. Hatiboglu, A. Bildstein, and T. Bauernhansl, "Industrie 4.0 roadmap: Framework for digitaltransformation based on the concepts of capability maturity and alignment. Procedia CIRP, 72 (51st CIRP Conference on Manufacturing Systems) ", 2018, pp. 973-978. DOI:10.1016/j.procir.2018.03.151.

[10] L. Novák and P. Doucek, "Regulation of Cyber Security in the Banking Sector", Proceedings of the International Conference IDIMT-2017 Digitalization in Management, Society and Economy, 2017 [Electronic resource]. Available at:http://idimt.org/wpcontent/uploads/proceedings/IDIMT_proceedings_ 2017.pdf.

[11] A. Pavlíček, R. Novák, L. Böhmová and S. Yabloschnikov, "Social media as a data source for human resources", IDIMT-2019. Innovation and Transformation in a Digital World, 27th Interdisciplinary Information Management Talks (Sept. 4-6, 2019), Kutná Hora, Czech Republic), TRAUNER Druck GmbH and Co KG, Linz, 2019, pp. 219-228.

[12] P. Sladek and M. Maryska, "Internet of things in energy industry. In IDIMT-2017-Digitalization in Management, Society and Economy-25th Interdisciplinary Information Management Talks", Edited by Doucek Petr, Chroust Gerhard and Oškrdal Vaclav. Linz: Trauner Verlag Universität, 2017, pp. 411-18. ISBN: 978-3-99062-119-6

[13] "Science and Technology", Innovation, Information Society: Pocket Data Book, 2017. 